\title{
Hepatitis C virus infection: accessing drug treatment
}

\author{
Dan Smyth MD, Duncan Webster MD
}

See also www.cmaj.ca/lookup/doi/10.1503/cmaj.150612 and www.cmaj.ca/lookup/doi/10.1503/cmaj.140290

$\mathrm{R}$ ecent approval of oral interferon-free treatment has created a unique opportunity to dramatically reduce complications and attendant costs of late-stage disease in people with hepatitis $\mathrm{C}$ virus (HCV) infection. When compared with the decreasing mortality associated with other chronic viral infections, mortality due to $\mathrm{HCV}$ infection continues to increase and has exceeded mortality due to HIV infection since $2007 .{ }^{1}$ A recent study in Ontario ranked HCV highest among all infectious diseases in terms of health-adjusted life years lost. ${ }^{2}$ A recent, well-conducted modelling study showed that, although HCV seroprevalence in Canada continues to decrease, the complications due to chronic $\mathrm{HCV}$ infection are set to increase substantially during the next two decades. ${ }^{3}$ Increases of $80 \%$ for decompensated cirrhosis, $205 \%$ for hepatocellular carcinoma and $160 \%$ for liver-related death, the latter peaking in 2034, are expected. Without increased access to treatment, an estimated 32460 people will die from liver-related complications over the next 20 years. Cure of HCV infection, or a sustained virologic response, is associated with reduced all-cause mortality and reduced rates of adverse outcomes, such as liver failure and hepatocellular carcinoma. ${ }^{4,5}$

Very high drug costs are offset by avoidance of costly late-stage complications and future transmission events; however, upfront expenditure is a challenging concept for any payer when the proposed cost savings may not accrue until decades later. Listings for novel, direct-acting antiviral drug treatments in Canada continue to be fibrosis-centred (i.e., reimbursement is available only to those patients with liver fibrosis at stage 2 or above). This strategy excludes many patients who may derive benefit from more urgent treatment. Furthermore, studies that model cost-effectiveness estimate direct medical costs only, and generally do not consider indirect costs and substantial impairments in quality of life associated with chronic HCV infection. Practically speaking, the physician is now presented with a curable transmissible infection for which well-tolerated treatment is now available but may not be readily accessible.

About two-thirds of HCV infections in Canada are genotype 1 , and response rates for interferon- based treatments for HCV infection of this genotype were inferior. ${ }^{6}$ Recently approved noninterferon-based oral regimens for treatment of genotype 1 infection achieved cure rates that consistently exceeded $90 \%$, including difficult-totreat patient populations, such as patients who are treatment-experienced and those with cirrhosis, generally without clinical or laboratory adverse events. ${ }^{7-10}$ Not surprisingly, these newly available treatments are in high demand.

Viewed through an economic lens, the "sweet spot" at which to initiate expensive treatment is population-dependent, and several variables influence cost-effectiveness: cost of treatment, prevalence of disease, risk of reinfection and underlying medical comorbidities, such as addiction and substance dependence. Among those patients with more advanced liver disease and at low risk for reinfection, the clinical and economic benefits of early treatment for HCV infection seem clear and measurable. However, for at-risk populations with a history of recent or ongoing illicit drug use, the economic advantage of early therapy and the ideal model of care are less clear. Data to guide treatment decisions in this population are limited. ${ }^{11}$ Furthermore, inadequate adherence to treatment, which may impact outcomes or increase susceptibility to reinfection following treatment, is a concern in this cohort.

Real-world prospective treatment and programming data are essential for all new regimens to address knowledge gaps. As part of the evaluation of treatment, it is important to measure societal outcomes and indirect costs, including impact on employment, health care utilization, reinfection

\section{KEY POINTS}

- Although HCV seroprevalence is decreasing in Canada, complications due to chronic HCV infection will continue to increase over the next 20 years.

- The high costs of novel treatments for HCV infection are offset through prevention of late-stage complications due to untreated disease and incident infections.

- The ideal initiation point for treatment is population-dependent, and several variables influence cost-effectiveness.

- Data from real-world prospective treatment are essential for all new regimens, including evaluation of treatment impact on employment, health care utilization, reinfection and patient-reported outcomes. 
and patient-reported outcomes. Such data will assist in the development of treatment protocols, in particular for thresholds of treatment initiation in people belonging to high-risk groups.

Prince Edward Island has led Canada in the creation of comprehensive clinical programming for patients with chronic HCV infection that is not based on the presence or absence of fibrosis. Key components of this program include centralized referral and triaging, which allows identification and prioritization of sicker patients, and also voluntary registration of all patients in the HEpatitis $\mathrm{C}$ positive and At-Risk database (HEAR) for evaluation of health outcomes.

Patients being treated in New Brunswick are also voluntarily enrolled into the HEAR database to measure both the clinical and economic impact of curative HCV treatment and indirect cost benefits, including effects on employment and patient-reported outcomes.

Clinical programs in New Brunswick will further address knowledge gaps through prospective analysis of the at-risk population of people who use illicit drugs, from which most incident cases in Canada currently arise. Pioneered in Saint John, the Centre for Research, Education, and Clinical Care of At-Risk Populations (RECAP) provides comprehensive and individualized patient care for people who inject drugs and cohorts of people who use illicit drugs. Treatment involving opiate substitution is used to stabilize opioid-dependant patients by employing a low-threshold, high-tolerance medical model of care that was previously validated. ${ }^{11} \mathrm{HCV}$ serostatus is determined at enrollment into the RECAP program and then annually if ongoing risk factors exist, with timely staging of disease in patients who are HCV positive. Following optimization of clinical, medical and psychosocial comorbidities, candidacy for treatment is determined using set clinical criteria. Under this treatment strategy, the clinic currently gives priority to at-risk patients with advanced fibrosis (F3/F4), HIV coinfection and extra-hepatic manifestations. Additional criteria for treatment include stability in methadone maintenance treatment and harm-reduction programs, if indicated. ${ }^{12}$ With moderate seroprevalence and high clinic retention rates, the RECAP program will actively engage and treat people who inject drugs, and aim to ascertain epidemiologic and economic impact through inclusive registration into the HEAR database. The ultimate aim is the creation of an agile mechanism to improve and alter the model of care to maximize clinical and cost benefits. Although disease progression may be less advanced in this cohort, cost savings may be observed through treatment as prevention with decreased transmission through a reduction of the $\mathrm{HCV}$-infection reservoir. If harm-reduction strate- gies prove successful in this cohort, high rates of viral clearance with direct-acting antiviral drugs in the real-world setting may promote a meaningful reduction in both $\mathrm{HCV}$ incidence and prevalence.

It is likely that maximum clinical and economic impact can be attained through dynamic programming that initially targets baby boomers with advanced disease and creates structured programming inclusive of treatment with directacting antiviral drugs in at-risk populations. The optimum threshold for initiation of treatment in people at high risk will depend on several factors, including community seroprevalence, risk of reinfection and engagement in harm-reduction measures. We call for the creation of a national treatment registry that captures data for patients with varying demographic characteristics, including community and academic treatment centres, with sampling from diverse at-risk population groups and metrics in place to gauge real-world clinical and economic impact, especially among marginalized populations.

\section{References}

1. Ly KN, Xing J, Klevens RM, et al. The increasing burden of mortality from viral hepatitis in the United States between 1999 and 2007. Ann Intern Med 2012;156:271-8.

2. Kwong JCCN, Crowcroft NS, Campitelli MS, et al. Ontario burden of infectious disease study. Toronto: Institute for Clinical Evaluative Sciences; 2010.

3. Myers RP, Krajden M, Bilodeau M, et al. Burden of disease and cost of chronic hepatitis C infection in Canada. Can J Gastroenterol Hepatol 2014;28:243-50.

4. Morgan TR, Ghany MG, Kim HY, et al. Outcome of sustained virological responders with histologically advanced chronic hepatitis C. Hepatology 2010;52:833-44.

5. Singal AG, Volk ML, Jensen D, et al. A sustained viral response is associated with reduced liver-related morbidity and mortality in patients with hepatitis C virus. Clin Gastroenterol Hepatol 2010;8:280-8

6. Antonishyn NA, Ast VM, McDonald RR, et al. Rapid genotyping of hepatitis $\mathrm{C}$ virus by primer-specific extension analysis. $J$ Clin Microbiol 2005;43:5158-63.

7. Feld JJ, Kowdley KV, Coakley E, et al. Treatment of HCV with ABT-450/r-ombitasvir and dasabuvir with ribavirin. $N$ Engl J Med 2014;370:1594-603.

8. Poordad F, Hezode C, Trinh R, et al. ABT-450/r-ombitasvir and dasabuvir with ribavirin for hepatitis $\mathrm{C}$ with cirrhosis. $N$ Engl J Med 2014;370:1973-82.

9. Zeuzem S, Jacobson IM, Baykal T, et al. Retreatment of HCV with ABT-450/r-ombitasvir and dasabuvir with ribavirin. $N$ Engl J Med 2014;370:1604-14.

10. Afdhal N, Zeuzem S, Kwo P, et al. Ledipasvir and sofosbuvir for untreated HCV genotype 1 infection. N Engl J Med 2014; 370:1889-98.

11. Christie TK, Murugesan A, Manzer D, et al. Evaluation of a low-threshold/high-tolerance methadone maintenance treatment clinic in saint john, new brunswick, Canada: one year retention rate and illicit drug use. J Addict 2013;2013:753409.

12. Smyth DJ, Webster D, Barrett L, et al. Transitioning to highly effective therapies for the treatment of chronic hepatitis $\mathrm{C}$ virus infection: a policy statement and implementation guideline. Can J Gastroenterol Hepatol 2014;28:529-34.

Affiliations: Department of Medicine (Smyth, Webster), Horizon Health, Moncton, NB; Division of Infectious Diseases, Department of Medicine (Smyth, Webster), Dalhousie University, Halifax, NS

Contributors: Both authors wrote and revised the article, gave final approval of the version to be published and agreed to act as guarantors of the work. 